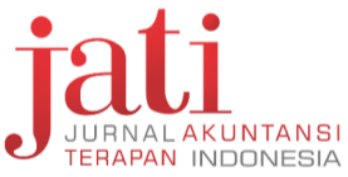

Jati: Jurnal Akuntansi Terapan Indonesia Vol 1 No 1 Hal 17-26 Maret 2018

\section{Implementasi Pernyataan Standar Akuntansi Keuangan 109 Pada Yayasan Rumah Yatim Arrohman: Identifikasi Faktor Pendukung}

\author{
http://journal.umy.ac.id/index.php/jati \\ C)2018 JATI. All rights reserved \\ DOI: 10.18196/jati.010102
}

\section{DATA ARTIKEL:}

Diterima: 02 Mar 2018

Direviu: 04 Mar 2018

Direvisi: 17 Mar 2018

Disetujui: 19 Mar 2018

TOPIK ARTIKEL:

Pelaporan Keuangan

\begin{abstract}
ABSTRAK: Tujuan penelitian ini untuk menganalisis kepatuhan laporan keuangan yang disiapkan Rumah Yatim Arrohman sesuai dengan Pernyataan Standar Akuntansi Keuangan (PSAK) Nomor 109 tentang Akuntansi Zakat. Metode yang digunakan adalah pendekatan deskriptif kualitatif dengan membandingkan antara laporan keuangan yang disusun Rumah Yatim Arrohman dan PSAK 109. Hasil penelitian ini menyimpulkan bahwa Rumah Yatim Arrohman sebagai salah satu Lembaga Amil Zakat Nasional (LAZNAS) sudah sepenuhnya menerapkan penggunaan PSAK 109 dalam menyajikan laporan keuangan. Faktor utama Rumah Yatim Arrohman mampu menyajikan laporan keuangan sesuai PSAK 109 adalah karena mereka memiliki manajemen organisasi pengelola zakat yang profesional dan telah memiliki software khusus untuk laporan keuangan, sehingga hal itu sangat memudahkan dalam praktik penyusunan laporan.
\end{abstract}

Kata Kunci: Laporan Keuangan; OPZ, PSAK 109; LAZNAS

ABSTRACT: The purpose of this study is to analyze the compliance of Yayasan Rumah Yatim Arrohman in preparing their financial statements ain ccordance with Pernyataan Standar Akuntansi Keuangan (PSAK) 109 about Zakah Accounting. The method used is qualitative descriptive approach by comparing the financial statements prepared by Rumah Yatim Arrohman and PSAK 109. The results of this study conclude that Rumah Yatim Arrohman as one of the National Amil Zakat Institute (LAZNAS) has fully applied PSAK 109 in presenting the financial statements. The main factor of Rumah Yatim Arrohman able to present financial statements in accordance with PSAK 109 is because they have a professional management of zakat management organization and already have special software for financial report, so it is very easy in practice of preparation of report.

\section{Keywords: Financial Report; OPZ; PSAK 109; LAZNAS}

\section{SITASI ARTIKEL:}

Hidayat, S., Rohaeni, N., \& Zanatun, A. (2018). Implementasi Pernyataan Standar AKuntansi Keuangan 109 pada Yayasan Rumah Yatim Arrohman. Jati: Jurnal Akuntansi Terapan Indonesia, 1(1), 17-26.

\section{PENDAHULUAN}

Penunaian Zakat merupakan rukun Islam ketiga yang wajib dilaksanakan oleh seorang muslim yang telah memenuhi syarat wajib zakat. Zakat merupakan kewajiban bagi setiap muslim yang mampu serta menjadi unsur dari rukun Islam, sedangkan infaq dan shadaqah merupakan wujud kecintaan hamba terhadap nikmat Allah SWT yang telah diberikan kepadanya sehingga seorang hamba rela menyisihkan sebagian hartanya untuk kepentingan agama baik dalam rangka membantu sesama maupun perjuangan dakwah Islam.

Di Indonesia, pengelolaan dana zakat telah diatur berdasarkan Undang-Undang Nomor 38 Tahun 1999 tentang Pengelolaan Zakat. Undang-Undang ini mengatur tentang Organisasi Pengelola Zakat (OPZ) yang boleh beroperasi di Indonesia. Dalam perkembangannya, untuk meningkatkan kualitas manajemen dan tata kelola OPZ, peme-rintah mengeluarkan Keputusan Menteri Agama (KMA) No. 333 Tahun 2015 tentang Pedoman Pemberian Izin Pembentukan Lembaga Amil Zakat. KMA tersebut diadakan dengan tujuan 
agar kedudukan OPZ semakin kuat. Selian itu KMA tersebut juga merupakan respon atas tuntutan kebutuhan agar OPZ menjalankan praktik tata kelola organisasi yang profesional serta mengarah kepada konsep New Public Management (NPM) (Rahman, 2015). Salah satu isu penting dari perkembangan OPZ adalah masalah pelaporan keuangan. Pelaporan keuangan menjadi alat untuk terwujudnya transparansi dan akunabilitas yang tujuan utamanya adalah hadirnya tata kelola yang baik di dalam OPZ. Dalam rangka hal tersebut, Ikatan Akuntan Indonesia (IAI) menerbitkan PSAK No. 109 pada 2010. Berlakunya PSAK 109 dalam pelaporan keuangan OPZ menjadi babak baru dalam perkembangan akuntabilitas lembaga zakat di Indonesia. Para akuntan publik dapat menjadikan PSAK 109 sebagai pedoman dalam melakukan audit atas laporan keuangan OPZ.

Sebagai salah satu lembaga amil zakat tingkat nasional (Laznas), Yayasan Rumah Yatim Arrohman terus berupaya meningkatkan nilai dan manfaat lembaga amil zakat di Indonesia dengan mengedepankan tata kelola zakat secara profesional. Oleh karena itu, penulis merasa perlu untuk melakukan penelitian pada Yayasan Rumah Yatim Arrohman dalam hal ini terkait pelaporan keuangan di OPZ tersebut. Logika rasionalnya adalah, sebagai salah satu Laznas, Rumah Yatim Arrohman tentu mendapatkan amanah uang yang sangat beasr dari masyarakat. Penelitian ini penting dilakukan mengingat meskipun PSAK No. 109 Akuntansi Zakat dan Infak/Sedekah telah dibuai IAI dan disahkan tepatnya pada tanggal 6 April 2010, akan tetapi masih banyak OPZ yang belum menerapkannya secara baik sebagaimana yang ditemukan pada beberapa penelitian terdahulu, yakni: Indrayani, Yuningsih dan Patitisahusiwa (2012), Umah (2011); Setiariware (2013); Istutik (2013); Pujianto (2015); Shahnaz (2015); dan Ritonga (2017).

Berangkat dari hal tersebut, maka penelitian ini bertujuan untuk mengetahui sejauh mana laporan keuangan Yayasan Rumah Yatim Arrohman telah sesuai dengan PSAK 109 tentang Akuntansi Zakat dan Infak/Sedekah. Kebaharuan penelitian ini terletak pada lokasi penelitian yang dilakukan pada Yayasan Yatim Arrohmah yang notabene berstatus sebagai OPZ nasional yang memeiliki banyak kantor cabang yang trsebar di Indonesia, dan juga ditambah dengan identifikasi faktor utama yang mendukung penerapan PSAK 109. Kerangka konseptual penelitian ini disajikan pada Gambar 1.

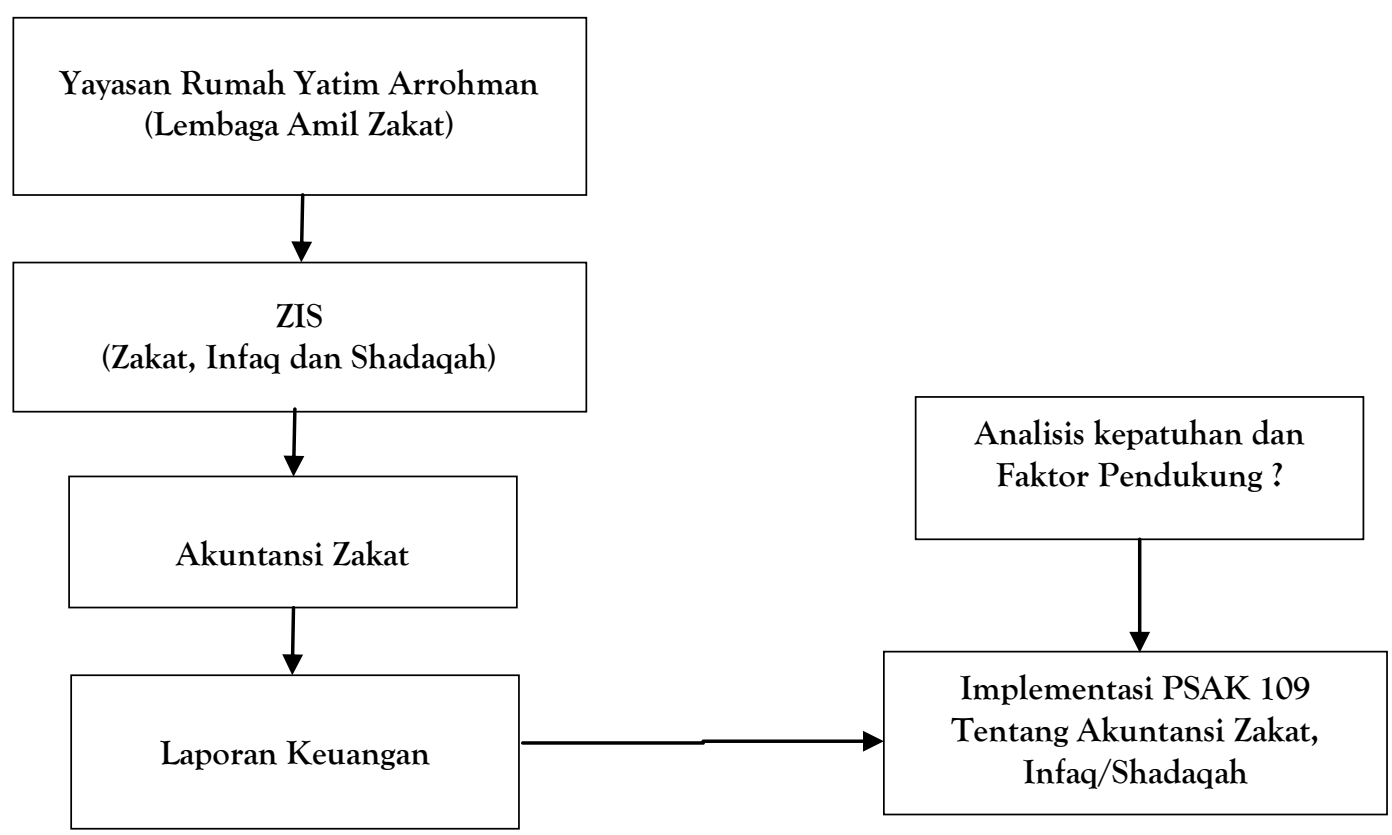

Gambar 1. Kerangka Konseptual Penelitian Sumber: Desain oleh peneliti 


\section{METODE PENELITIAN}

Objek dalam penelitian laporan keuangan Yayasan Rumah Yatim Arrohman yang beralamat kantor pusat di Jln. Terusan Jakarta No. 212, Antapani - Bandung Jawa Barat. Yayasan Rumah Yatim Arrohman sendiri adalah Lembaga Amil Zakat Nasional (LAZNAS) milik masyarakat indonesia yang berkhidmat mengangkat harkat sosial kemanusiaan yatim dhuafa dengan dana ZISWAF (Zakat, Infaq, Shadaqah, Wakaf) serta dana lainnya yang halal dan legal, dari perorangan, kelompok, perusahaan/ lembaga yang telah memiliki legalitas yang resmi yaitu Akta Notaris tahun 2007, SK Kemenkumham RI, dan Surat Ijin Dinas Sosial Kota Bandung tahun 2013 dan Dinas Sosial Provinsi Jawa Barat tahun 2011. Lembaga ini memiliki kepercayaan yang besar dari masyarakat Indonesia sebagai lembaga pengumpul zakat di Indonesia yang cabangnya hampir tersebar di seluruh Provinsi di Indonesia bahkan luar negeri. Oleh karena itu peneliti tertarik meneliti di Yayasan Rumah Yatim Arrohman.

Jenis data yang digunakan adalah data sekunder yaitu berupa data laporan keuangan Yayasan Rumah Yatim Arrohman. Sedangkan laporan keuangan yang digunakan adalah laporan posisi keuangan per 31 Desember tahun 2016 dan 2015. Metode analisis yang digunakan dalam penelitian ini adalah deksriptif kualitatif dengan analisis kepatuhan, yakni mendeskripsikan atau menggambarkan keadaan objek penelitian yang sesungguhnya untuk mengetahui dan menganalisis tentang penerapan akuntansi zakat, infak/shadaqah pada objek penelitian kemudian disamakan dengan standar yang ada (Ali, 2015), dalam hal ini PSAK 109.

Dalam penelitian ini, peneliti mendeskripsikan penerapan akuntansi zakat dan infak/shadaqah pada Yayasan Rumah Yatim Arrohman. Data yang dikumpulkan dianalisis dengan membandingkan akuntansi zakat dan infak /shadaqah yang diterapkan pada Yayasan Rumah Yatim Arrohman dengan PSAK 109, Komponen yang dianalisis yaitu Laporan Posisi Keuangan, Dana Laporan Perubahan, Laporan Perubahan Aset Kelolaan, Laporan Arus Kas dan Catatan atas Laporan Keuangan. Selain dari komponen analisis tersebut peneliti mengkaji faktor pendukung dalam penerapan kepatuhan PSAK 109 di Yayasan Rumah Yatim Arrohman.

\section{HASIL DAN PEMBAHASAN}

Yayasan Rumah Yatim Arrohman menggunakan PSAK 109 sebagai pedoman dalam membuat laporan keuangan. Dalam laporan keuangan Yayasan Rumah Yatim Arrohman ini telah di Audit sebelumnya. Analisis komponen Laporan Keuangan Yayasan Rumah Yatim Arrohman diuraikan sebagai berikut:

\section{Laporan Posisi Keuangan}

Dari hasil analisis, ditemukan bahwa di dalam Laporan Posisi Keuangan, Yayasan Rumah Yatim Arrohman menyajikan posisi aset, kewajiban, dan saldo dana per tanggal laporan. Penyajian aset dan kewajiban tidak terlalu berbeda dengan laporan posisi keuangan organisasi lainnya. Namun, pada laporan posisi keuangan OPZ bagian modal diganti dengan saldo dana. Saldo dana mencerminkan aktiva kelolaan (baik lancar maupun tidak lancar) yang dimiliki oleh OPZ tahunan Yayasan Rumah Yatim Arrohman disajikan pada Gambar 2 dan 3.

Format laporan keuangan Yayasan Rumah Yatim Arrohman menggunakan format dua kolom dengan menyajikan tahun 2015 dan tahun 2016. Penyajian ini memudahkan pembaca laporan keuangan untuk melihat seberapa besar posisi keuangan dari tahun 2015-2016. Format laporan posisi keuangan Yayasan Rumah Yatim Arrohman sebagai laporan utama sudah sesuai dengan yang diatur pada lampiran PSAK 109. Dilihat dari laporan keuangan Yayasan Rumah Yatim Arrohman merinci saldo dana yang terdiri dari saldo dana zakat, infak/sedekah, dan saldo dana amil. Biaya yang masih harus dibayar termasuk dalam kewajiban lancar. Kewajiban employment benefit masuk dalam kewajiban jangka panjang.

\section{Penyajian Aktiva dan Kewajiban}

Dalam penyajian laporan posisi keuangan, Yayasan Rumah Yatim Arrohman menyajikan akunakun aktiva sesuai dengan urutan likuiditasnya, dari yang paling likuid yaitu kas dan setara kas, sampai yang paling tidak likuid, yaitu aset tetap. Untuk kewajiban, akun disajikan dari kewajiban jangka pendek ke kewajiban jangka panjang. Hal ini sudah sesuai dengan contoh format laporan posisi keuangan pada PSAK 109. Aktiva tetap disajikan dalam nilai buku, penjelasan dari aktiva tetap dan akumulasi penyusutannya bisa dibaca dari catatan atas laporan keuangan.

\section{Penyajian Saldo Dana}

Saldo dana dalam PSAK 109 adalah selisih dari aktiva dan kewajiban. Saldo dana terdiri dari dana zakat, dana infak/sedekah, dan dana amil. Pengklasifikasian saldo dana tersebut dilakukan sesuai dengan sumber penerimaan dana pada OPZ. Dalam 
laporan ini, disajikan saldo dana dari dana zakat, infak/sedekah, dan dana amil. Hal ini telah sesuai dengan PSAK 109.

\section{Laporan Perubahan Dana}

Laporan Perubahan Dana adalah laporan yang menggambarkan kinerja organisasi, yang meliputi penerimaan dan penggunaan dana pada suatu periode tertentu. Laporan perubahan dana Rumah Yatim Arrohman disajikan pada Gambar 4, 5 dan 6. Penulis berpendapat Yayasan Rumah Yatim Arrohman membuat Laporan Perubahan Dana sesuai format yang tertera di lampiran PSAK 109. Karena secara tidak langsung laporan perubahan dana Yayasan Rumah Yatim Arrohman sudah lengkap dan jelas dari tahun 2015-2016.

\begin{tabular}{|c|c|c|c|}
\hline \multicolumn{4}{|c|}{$\begin{array}{l}\text { YAYASAN RUMAH YATIM ARROHMAN INDONESIA } \\
\text { LAPORAN POSISI KEUANGAN } \\
\text { PER } 31 \text { DESEMBER } 2016 \text { DAN } 2015\end{array}$} \\
\hline POS-POS LAPORAN POSISI KEUANGAN & CTT & 2016 & 2015 \\
\hline \multicolumn{4}{|l|}{ ASET } \\
\hline \multicolumn{4}{|l|}{ ASET LANCAR } \\
\hline Kas dan Setara Kas & $2 c, 3$ & $14,671,491,342$ & $6,765,997,515$ \\
\hline Piutang Internal & $2 \mathrm{e}, 4$ & $228,694,651$ & $332,110,350$ \\
\hline Piutang Lain - lain & $2 e, 5$ & $155,350,000$ & $153,000,000$ \\
\hline Persediaan & $2 f, 6$ & $131,551,108$ & - \\
\hline Uang Muka Kegiatan & 7 & $1,693,226,885$ & $1,375,843,242$ \\
\hline Pajak Dibayar Dimuka & $2 m, 8$ & $28,347,928$ & - \\
\hline Beban Dibayar Dimuka & $2 \mathrm{~g}, 9$ & $3,223,493,750$ & $3,612,505,974$ \\
\hline Jumlah Aset Lancar & & $20,132,155,665$ & $12,239,457,081$ \\
\hline \multicolumn{4}{|l|}{ ASET TIDAK LANCAR } \\
\hline Aset Tetap & $2 \mathrm{~h}, 10$ & & \\
\hline Bangunan & & $1,715,000,000$ & $1,715,000,000$ \\
\hline Peralatan & & $2,952,928,435$ & $2,673,353,833$ \\
\hline Perlengkapan & & $2,975,093,524$ & $2,977,918,524$ \\
\hline \multicolumn{2}{|l|}{ Jumlah Nilai Perolehan } & $\begin{array}{r}3,267,461,749 \\
10,910,483,708\end{array}$ & $\begin{array}{l}2,234,458,025 \\
\mathbf{9}, 600,730,382\end{array}$ \\
\hline Akumulasi Penyusutan & & $(7,260,266,190)$ & $(5,485,722,278)$ \\
\hline Nilai Buku & & $3,650,217,518$ & $4,115,008,104$ \\
\hline Aset Tidak Lancar Kelolaan & $2 \mathrm{j}, 11$ & & \\
\hline Tanah & & $8,779,170,772$ & $12,265,786,206$ \\
\hline Bangunan & & $2,951,603,329$ & $13,890,974,576$ \\
\hline Kendaraan & & - & $1,800,087,100$ \\
\hline Peralatan dan Perlengkapan & & $132,223,275$ & - \\
\hline \multicolumn{2}{|l|}{ Jumlah Nilai Perolehan } & $11,862,997,375$ & $27,956,847,882$ \\
\hline Akumulasi Penyusutan & & $(1,431,883,061)$ & $(2,589,992,944)$ \\
\hline Nilai Buku & & $10,431,114,314$ & $25,366,854,938$ \\
\hline Aset Tidak Lancar Lainnya & $2 \mathrm{j}, 12$ & & \\
\hline Tanah Dalam Penyelesaian & & - & $7,479,100,000$ \\
\hline Bangunan Dalam Penyelesaian & & $379,097,997$ & $781,842,742$ \\
\hline \multicolumn{2}{|l|}{ Jumlah Aset Tidak Lancar Lainnya } & $379,097,997$ & $8,260,942,742$ \\
\hline JUMLAH ASET & & $34,592,585,494$ & $49,982,262,865$ \\
\hline $\begin{array}{l}\text { Lihat catatan atas laporan keuangan merupakan bag } \\
\text { secara kes }\end{array}$ & $\begin{array}{l}\text { yang } t \\
\text { uhan }\end{array}$ & rpisahkan dari lap & an keuangan \\
\hline
\end{tabular}

Gambar 2. Laporan Posisi Keuangan

Sumber: Laporan Keuangan OPZ Rumah Yatim Arrohman 2016 dan 2015 


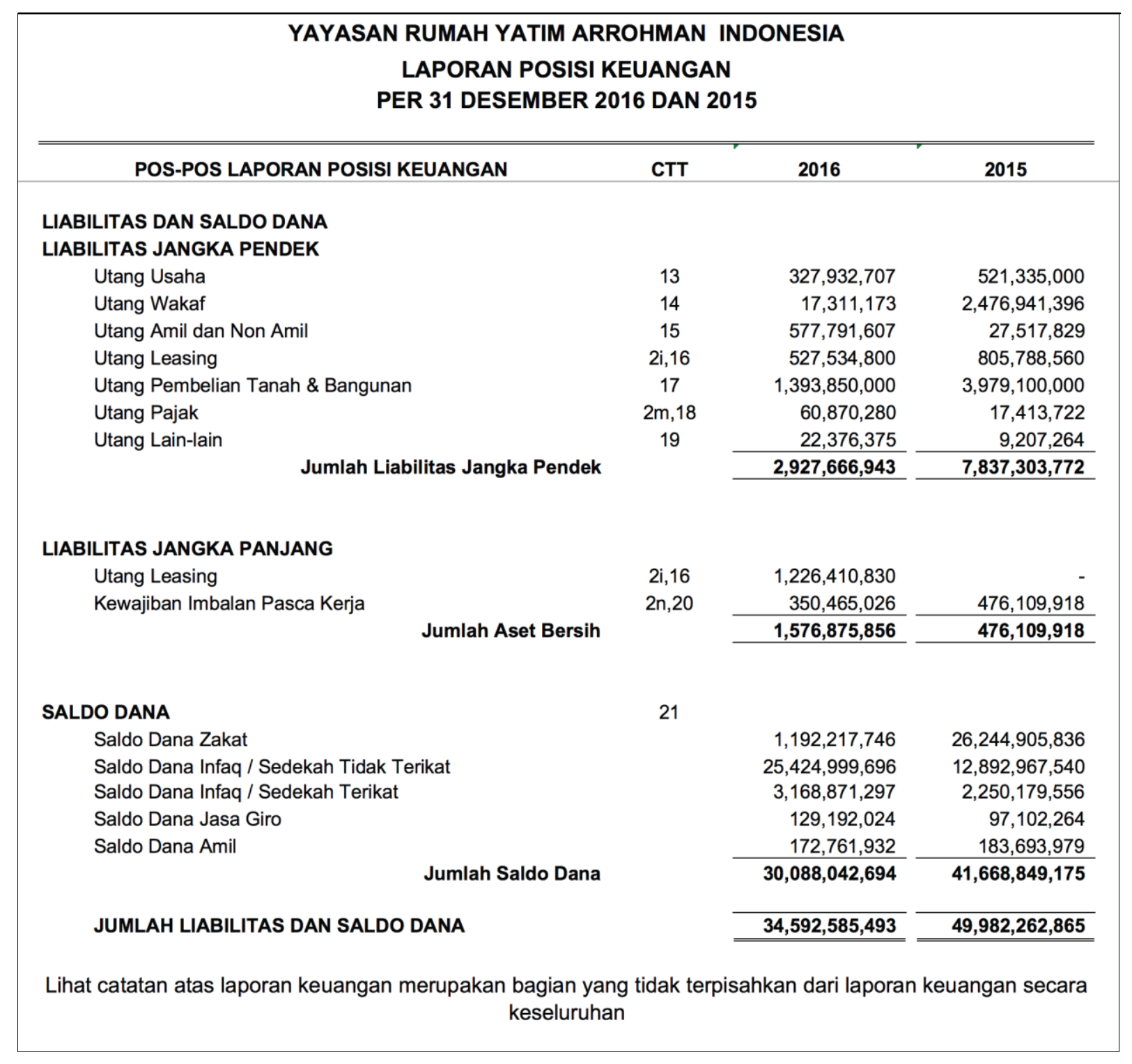

Gambar 3. Laporan Posisi Keuangan

Sumber: Laporan Keuangan OPZ Rumah Yatim Arrohman 2016 dan 2015 


\begin{tabular}{|c|c|c|c|}
\hline \multicolumn{4}{|c|}{$\begin{array}{l}\text { YAYASAN RUMAH YATIM ARROHMAN INDONESIA } \\
\text { LAPORAN PERUBAHAN DANA } \\
\text { Untuk periode } 01 \text { Januari } 2015 \text { s/d } 31 \text { Desember } 2016 \text { dan } 2015\end{array}$} \\
\hline KETERANGA N & CTT & $\begin{array}{c}2016 \\
\text { (Rupiah) }\end{array}$ & $\begin{array}{c}2015 \\
\text { (Rupiah) }\end{array}$ \\
\hline a. DANA ZAKAT & 21,22 & & \\
\hline \multicolumn{4}{|l|}{ Penerimaan Dana Zakat: } \\
\hline \multirow[t]{2}{*}{ Penerimaan Zakat } & & $19,794,426,549$ & $17,134,212,301$ \\
\hline & & $19,794,426,549$ & $17,134,212,301$ \\
\hline \multicolumn{4}{|l|}{ Penyaluran Dana Zakat : } \\
\hline - Penyaluran Fakir & & - & $4,343,128,712$ \\
\hline - Penyaluran Miskin & & - & $5,301,558,085$ \\
\hline - Penyaluran Fakir Miskin & & $18,462,984,568$ & - \\
\hline - Penyaluran Fisabilillah & & $23,902,031,753$ & $2,797,312,890$ \\
\hline - Penyaluran Ibnu Sabil & & $5,445,000$ & $72,255,000$ \\
\hline - Penyaluran Muallaf & & $2,362,000$ & - \\
\hline - Penyaluran Bagian Amil dari Dana Zakat & & $2,473,904,069$ & $2,142,031,975$ \\
\hline \multirow[t]{2}{*}{ - Selisih Kurang Penilaian - Dana Zakat } & & 387,250 & - \\
\hline & & $44,847,114,639$ & $14,656,286,663$ \\
\hline Surplus/Defisit & & $(25,052,688,090)$ & $2,477,925,638$ \\
\hline Saldo Awal & & $26,244,905,836$ & $23,766,980,198$ \\
\hline Saldo Akhir & & $1,192,217,746$ & $26,244,905,836$ \\
\hline b. DANA INFAQ / SEDEKAH TIDAK TERIKAT & 21,23 & & \\
\hline \multirow[t]{2}{*}{$\begin{array}{l}\text { Penerimaan Dana Infaq/Shodaqoh Umum: } \\
\text { - Penerimaan Infaq / Sodaqoh Umum } \\
\text { - Selisih lebih Penilaian - Dana Infaq/Shodaqoh Umum }\end{array}$} & & $\begin{array}{r}45,976,417,065 \\
366,430\end{array}$ & $\begin{array}{r}39,761,205,594 \\
-\end{array}$ \\
\hline & & $45,976,783,495$ & $39,761,205,594$ \\
\hline \multicolumn{4}{|l|}{ Penyaluran Dana Infaq/Shodaqoh Umum: } \\
\hline - Penyaluran Insentif Program & & $10,437,667,814.60$ & $9,061,301,603$ \\
\hline - Penyaluran Program Keasramaan (Lihat Lamp. 1) & & $7,850,949,539.30$ & $8,901,291,097$ \\
\hline - Penyaluran Program Sekolah & & $832,171,473.58$ & $5,056,203,810$ \\
\hline - Penyaluran Program Beasiswa Dhuafa & & $1,829,984,500.00$ & $3,568,979,500$ \\
\hline - Penyaluran Program Klinik (Lihat Lamp. 2) & & $934,145,273.70$ & $674,267,561$ \\
\hline - Penyaluran Program Bantuan Masjid \& Madrasah & & $116,625,000.00$ & - \\
\hline - Penyaluran Program Bantuan Bahan Pokok & & $23,320,000.00$ & - \\
\hline - Penyaluran Pemeliharaan & & $251,109,350.02$ & - \\
\hline - Penyaluran Sosprom & & $1,902,801,109.00$ & $2,706,757,461$ \\
\hline - Penyaluran Bagian Amil dari Dana Infaq/Shodaqoh Umum & & $6,806,368,394.94$ & $5,754,184,394$ \\
\hline - Penyaluran kepada Amil & & - & $1,550,000,000$ \\
\hline - Penyaluran Penyusutan Bangunan Kelolaan & & $1,621,043,962.03$ & $1,213,590,350$ \\
\hline - Penyaluran Penyusutan Kendaraan Kelolaan & & $584,985,868.75$ & $421,714,525$ \\
\hline - Penyaluran Penyusutan Peralatan Kelolaan & & $224,962,676.26$ & - \\
\hline - Penyaluran Penyusutan Perlengkapan Kelolaan & & $23,690,230.63$ & - \\
\hline \multirow[t]{2}{*}{ - Selisih Kurang Penilaian - Dana Infaq/Shodaqoh Umum } & & $4,926,147.00$ & - \\
\hline & & $33,444,751,340$ & $38,908,290,300$ \\
\hline Surplus/Defisit & & $12,532,032,155$ & $852,915,294$ \\
\hline Saldo Awal & & $12,892,967,540$ & $12,040,052,246$ \\
\hline Saldo Akhir & & $25,424,999,695$ & $12,892,967,540$ \\
\hline
\end{tabular}

Gambar 4. Laporan Perubahan Dana

Sumber: Laporan Keuangan OPZ Rumah Yatim Arrohman 2016 dan 2015 


\begin{tabular}{|c|c|c|c|}
\hline \multicolumn{4}{|c|}{$\begin{array}{l}\text { YAYASAN RUMAH YATIM ARROHMAN INDONESIA } \\
\text { LAPORAN PERUBAHAN DANA } \\
\text { Untuk periode 01 Januari } 2015 \text { s/d } 31 \text { Desember } 2016 \text { dan } 2015\end{array}$} \\
\hline KETERANG A N & Стт & $\begin{array}{c}2016 \\
\text { (Rupiah) }\end{array}$ & $\begin{array}{c}2015 \\
\text { (Rupiah) }\end{array}$ \\
\hline c. DANA INFAQ / SEDEKAH TERIKAT & 21,24 & & \\
\hline $\begin{array}{l}\text { Penerimaan Dana Infaq/Shodaqoh Khusus: } \\
\text { - Penerimaan Infaq/Shodaqoh Khusus }\end{array}$ & & 6.791 .732 .785 & $2.225,883,823$ \\
\hline - Penerimaan Agigah & & $453,294,000$ & $253,650,000$ \\
\hline - Penerimaan Qurban & & $1,335,679,000$ & $983,466,274$ \\
\hline \multirow{2}{*}{ - Penerimaan Hibah } & & $1,500,000$ & $3,655,000$ \\
\hline & & $8,582,205,785$ & $3,466,655,097$ \\
\hline \multicolumn{4}{|l|}{ Penyaluran Dana Infaq/Shodaqoh Khusus : } \\
\hline - Penyaluran untuk aqiqah & & $455,221,133$ & $241,005,900$ \\
\hline - Penyaluran untuk qurban & & $1,164,047,608$ & $1,053,236,378$ \\
\hline - Penyaluran untuk kafarat & & $8,227,661$ & - \\
\hline - Penyaluran untuk fidyah & & $414,121,920$ & - \\
\hline - Penyaluran untuk nadzar & & $841,982,406$ & $3,500,000$ \\
\hline - Penyaluran untuk program & & $4,740,372,816$ & $961,823,484$ \\
\hline - Penyaluran untuk hibah & & - & $30,913,800$ \\
\hline \multirow[t]{2}{*}{ - Penyaluran untuk program dokter yatim } & & $39,540,500$ & $128,713,937$ \\
\hline & & $7,663,514,044$ & $2,419,193,499$ \\
\hline Surplus/Defisit & & $918,691,741$ & $1,047,461,598$ \\
\hline Saldo Awal & & $2,250,179,556$ & $1,202,717,958$ \\
\hline Saldo Akhir & & $3,168,871,297$ & $2,250,179,556$ \\
\hline d. DANA JASA GIRO & 21,25 & & \\
\hline Penerimaan Jasa Giro & & $105,903,657$ & $83,698,294$ \\
\hline \multirow[t]{2}{*}{ Penerimaan Non Halal } & & $2,940,000$ & \\
\hline & & $108,843,657$ & $83,698,294$ \\
\hline Penyaluran Dana Jasa Giro & & $76,753,897$ & $74,410,063$ \\
\hline Surplus/Defisit & & $32,089,760$ & $9,288,231$ \\
\hline Saldo Awal & & $97,102,264$ & $87,814,033$ \\
\hline Saldo Akhir & & $129,192,024$ & $97,102,264$ \\
\hline
\end{tabular}

Gambar 5. Laporan Perubahan Dana

Sumber: Laporan Keuangan OPZ Rumah Yatim Arrohman 2016 dan 2015 


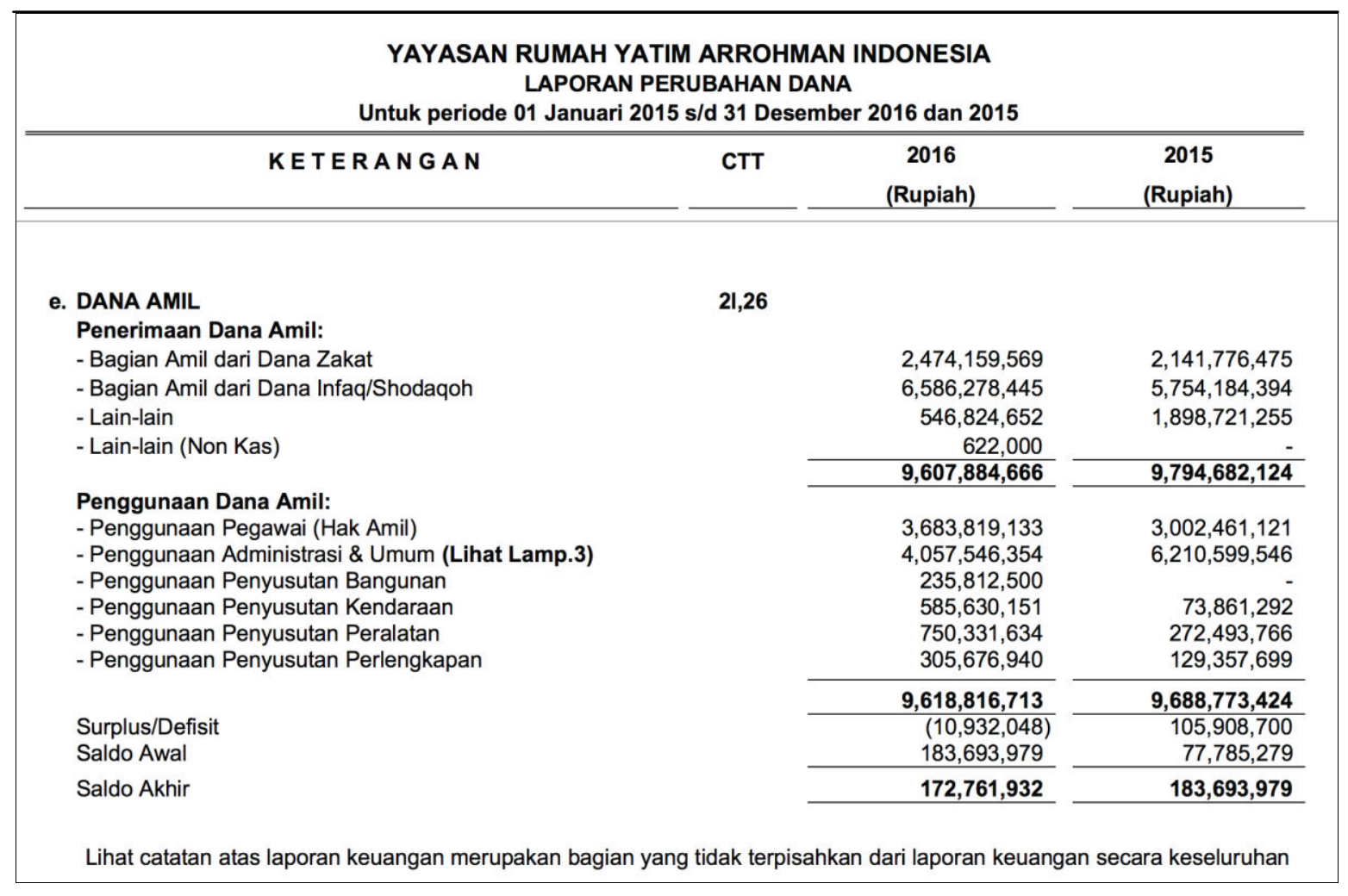

Gambar 6. Laporan Perubahan Dana

Sumber: Laporan Keuangan OPZ Rumah Yatim Arrohman 2016 dan 2015

\section{Laporan Arus Kas}

Laporan arus kas adalah laporan yang menggambarkan arus kas masuk dan keluar pada suatu periode tertentu. Tujuannya adalah untuk menyajikan informasi mengenai penerimaan dan pengeluaran kas organisasi pada suatu periode tertentu. Laporan arus kas Yayasan Rumah Yatim Arrohman disusun dengan metode langsung (direct method) dengan mengelompokkan arus kas dalam aktivitas operasi, investasi dan pendanaan. Dalam pembuatan laporan arus kas, Yayasan Rumah Yatim Arrohman berpedoman kepada PSAK 2 tentang laporan arus kas, sehingga laporan arus kas Yayasan Rumah Yatim Arrohman sudah sesuai denganPSAK 109.

\section{Catatan Atas Laporan Keuangan}

Catatan Atas Laporan Keuangan merupakan rincian atau penjelasan detail dari laporan keuangan sebelumnya yang dapat bersifat kuantitatif dan kualitatif. Dalam Catatan Atas Laporan Keuangan Yayasan Rumah Yatim Arrohman diterangkan berbagai catatan dan penjelasan dari laporan keuangan yang disajikan. Catatan Atas Laporan Keuangan adalah bagian yang tidak terpisahkan dari laporan keuangan Yayasan Rumah Yatim Arrohman secara utuh. Catatan Atas Laporan Keuangan juga merupakan salah satu bentuk pengungkapan Yayasan Rumah Yatim Arrohman terhadap kebijakan, aktivitas, dan keuangannya. Dari analisa penulis, Laporan yang dibuat oleh Yayasan Rumah Yatim Arrohman sudah cukup informative dan bisa menjelaskan dari laporan secara keseluruhan.

\section{Analisis Penerapan PSAK 109 pada Yayasan Rumah Yatim Arrohman}

Pada pencatatan akuntansi dan pelaporan Yayasan Rumah Yatim Arrohman telah menerapkan aturan-aturan yang terdapat dalam PSAK 109. Dalam menyusun pelaporan keuangan, Yayasan Rumah Yatim Arrohman mengacu pada PSAK 109 dan implementasinya sudah sesuai dengan yang disyaratkan dalam PSAK 109. Laporan keuangan Yayasan Rumah Yatim Arrohman diterbitkan tahunan. Laporan tahunan mengungkapkan laporan keuangan lebih lengkap yang terdiri dari laporan posisikeuangan, laporan perubahan dana, laporan perubahan aset kelolaan, laporan aruskas, dan catatan atas laporan keuangan. Dari hasil temuan penelitian, eneliti mrangkumnya sebagaimana yang disajikan pada Tabel 1. 
Tabel 1. Penerapan PSAK 109 pada Yayasan Rumah Yatim Arrohman

\begin{tabular}{|c|c|c|}
\hline PSAK 109 & Pelaksanaan pada Yayasan & Kesesuaian \\
\hline \multicolumn{3}{|c|}{ ZAKAT } \\
\hline $\begin{array}{l}\text { Amil menyajikan dana zakat, dana infak, } \\
\text { dan dana amil secara terpisah dalam } \\
\text { laporan posisi keuangan. }\end{array}$ & $\begin{array}{l}\text { Dalam laporan Yayasan Rumah Yatim } \\
\text { Arrohman yang khusus LAZ, laporan posisi } \\
\text { keuangan menyajikan dana zakat, dana } \\
\text { infak, dan dana amil secara terpisah. }\end{array}$ & Sesuai \\
\hline $\begin{array}{l}\text { Penggunaan dana zakat/infak dalam } \\
\text { bentuk asset kelolaan. Diungkapkan jumlah } \\
\text { persentase terhadap seluruh penyaluran } \\
\text { dana zakat dan alasannya. }\end{array}$ & $\begin{array}{l}\text { Mengenai aset kelolaan dapat dilihat di } \\
\text { dalam laporan keuangan tahunan Yayasan } \\
\text { Rumah Yatim Arrohman }\end{array}$ & Sesuai \\
\hline $\begin{array}{l}\text { Hubungan pihak-pihak berelasi antara amil } \\
\text { dan mustahik yang meliputi sifat } \\
\text { hubungan, jumlah dan jenis aset yang } \\
\text { disalurkan, dan presentase dari setiap aset } \\
\text { yang disalurkan tersebut dari total } \\
\text { penyaluran zakat selama periode. }\end{array}$ & $\begin{array}{l}\text { Yayasan Rumah Yatim Arrohman } \\
\text { menjelaskan di CALK mengenai jejaring } \\
\text { yang digunakan untuk menyalurkan zakat, } \\
\text { jumlah dan jenis. }\end{array}$ & Sesuai \\
\hline
\end{tabular}

INFAK/SHADAQAH

Kebijakan penyaluran infak/sedekah seperti penentuan skala prioritas penyaluran infak/sedekah dan penerima infak/sedekah.

Kebijakan penyaluran infak dan sedekah untuk amil dan nonamil, seperti persentase pembagian, alasan, dan konsistensi kebijakan.

Hasil yang diperoleh dari pengelolaan dana infak dan sedekah diungkapkan secara terpisah.

\section{Dalam CALK diungkapkan skala prioritas} penyaluran dan penerimaan infak/sedekah.

Sesuai

Dalam CALK diungkapkan mengena

Sesuai kebijakan penyaluran untuk amil dan nonamil, persentase pembagiannya.

Dalam laporan keuangan tahunan yang

Sesuai lengkap diungkap hasil pengelolaan dana infak/sedekah.
Dari hasil analisis atas laporan keuangan Yayasan Rumah Yatim Arrohman, dapat dismpulkan bahwa pelaporan keuangan Yayasan Rumah Yatim Arrohman sudah sesuai dengan apa yang telah digariskan dalam PSAK 109. Menurut penulis, laporan keuangan Yayasan Rumah Yatim Arrohman sudah baik dan informatif bagi pembaca laporan keuangan. Hasil penelitian ini sesuai dengan penelitian yang telah dilakukan oleh Yulyani (2012) yang juga menemukan bahwa beberapa OPZ sudah dapat menerapkan PSAK 109 dengan sesuai.

Dalam penerapan kepatuhan pada PSAK 109, Yayasan Rumah Yatim Arrohman memiliki pendukung dan penghambat selama proses kepatuhan PSAK 109 ini. Berdasarkan hasil pengamatan peneliti bahwa faktor pendukung diantaranya ialah, pertama manajemen organisasi pengelola zakat yang profesional, mengedepankan prinsip amanah dan transparan terhadap masyarakat. Faktor kedua adalah OPZ ini telah memiliki software khusus untuk laporan keuangan sehingga memudahkan praktik penyusunan laporan keuangan, khususnya konsolidasi laporan-laporan keuangan cabang menjadi satu.

\section{SIMPULAN}

Berdasarkan hasil penelitian, dapat disimpulkan bahwa laporan keuangan Yayasan Rumah Yatim Arrohman sudah sesuai dengan Pernyataan Standar Akuntansi Keuangan (PSAK) No. 109. Adapun yang menjadi faktor pendukung dari implementasi PSAK 109 yang sudah sesuai ini diantaranya ialah manajemen organisasi pengelola zakat yang profesional dan adanya bantuan dari software khusus untuk pelaporan keuangan. Dari hasil penelitian ini maka implikasi penting yang dapat dijadikan masukan bagi OPZ lain di Indonesia adalah penting untuk menerapkan pola manajemen yang baik guna mendukung akuntabilitas yang baik pula. Selain itu, 
kehadiran alat bantu berupa sistem informasi akuntansi sangat disarankan agar proses penyusunan laporan keuangan dapat berjalan lebih mudah.

Penelitian ini memiliki keterbatasan yakni masih terfokus pada pencarian faktor pendukung implementasi PSAK 109 di Lazsnas. Penelitian selanjutnya dapat mengkaji dan mengksplorasi lebih dalam tentang faktor penghambat implementasi PSAK 109 pada OPZ dengan level berbeda, misalnya OPZ di level kabupaten/kota atau daerah (provinsi).

\section{DAFTAR PUSTAKA}

Ali, M. C. (2015). Analisis Penerapan PSAK No. 48 (Revisi 2013) Penurunan Nilai Aset Tetap Pada PT. Bank Sulut. Jurnal Berkala Ilmiah Efisiensi, 15(3).

Ikatan Akuntan Indonesia. (2011). Pernyataan Standar Akuntansi Keuangan No.109 Akuntansi Zakat dan Infak/Sedekah. Jakarta: Ikatan Akuntan Indonesia.

Istutik. (2013). Analisis Implementasi Akuntansi Zakat Dan Infak/Sedekah (PSAK:109) Pada Lembaga Amil Zakat Di Kota Malang. Jurnal Akuntansi Aktual, 5(1).

Keputusan Menteri Agama (KMA) No. 333 Tahun 2015 tentang Pedoman Pemberian Izin Pembentukan Lembaga Amil Zakat.

Pujianto (2015). Implementasi PSAK 109 Tentang Akuntansi Zakat dan Infak/Sedekah (Studi Empiris Pada Organisasi Pengelola Zakat dan Infak/Sedekah pada Kota Semarang). Jurnal Universitas Negeri Semarang, 9(1).

Rahman, T. (2015). Akuntansi Zakat, Infak dan Sedekah (PSAK 109): Upaya Peningkatan Transparansi dan Akuntabilitas Organisasi Pengelola Zakat (OPZ). Jurnal Muqtasid, 6(1), 141-164.

Ritonga, P. (2017). Analisis Akuntansi Zakat Berdasarkan PSAK No. 109 Pada Badan Amil Zakat Nasional (BAZNAS) Sumatera Utara. KITABAH, 1(1), 1-19.

Setiariware, A. M. (2013). Analisis Penerapan Akuntansi Zakat, Infak dan Sedekah pada LAZ (Lembaga Amil Zakat) Dompet Dhuafa Cabang Makasar. Skripsi, Universitas Hasanuddin.

Umah, U. K. (2011). Penerapan Akuntansi Zakat Pada Lembaga Amil Zakat (Studi pada LAZ DPU DT Cabang Semarang). Skripsi, Institut Agama Islam Negeri Walisongo Semarang.

UU No. 38 tentang Pengelolaan Zakat. Jakarta: Forum Zakat.

Yulyani, I. I. (2012). Analisis Pencatatan Dan Pelaporan Laporan Keuangan Bazis Provinsi DKI Jakarta
Dengan Acuan PSAK 109. Skripsi, Universitas Gunadarma. 